\title{
Exposure and Response Prevention in the Treatment of Body Dysmorphic Disorder: A Case Series
}

\section{FREDRIK FOLKE $^{\mathrm{a}}$, MARI VON BAHR ${ }^{\mathrm{b}}$, VANDAD ASSADI-TALAREMI, ${ }^{\mathrm{b}}$ \& JONAS RAMNERÖ ${ }^{\mathrm{b}, \mathrm{c}}$}

\author{
a Department of Neuroscience, Psychiatry, University Hospital, Uppsala \\ b \\ Department of Psychology, Stockholm University, Stockholm \\ ${ }^{\mathrm{C}}$ Correspondence regarding this article should be addressed to Fredrik Folke, Center for Clinical Research Dalarna, \\ Nissers väg 3, SE-79182 Falun, Sweden \\ email: fredrik.folke@neuro.uu.se
}

\begin{abstract}
This case study series investigates the effect of Exposure and Response Prevention in relation to other components present in behavioral therapy for Body Dysmorphic Disorder (BDD). Treatment components were added one at a time in four consecutive phases: $\left(\mathrm{A}_{1}\right)$ SelfMonitoring; (B) Therapist Contact; (C) Exposure and Response Prevention (ERP); and, $\left(\mathrm{A}_{2}\right)$ Renewed Self-Monitoring. Client assessment involved (a) a daily self-report diary of BDD symptoms throughout treatment, and (b) periodic completion of standardized self-report measures tapping BDD symptoms and related symptoms of depression and global functioning. In all, six clients participated in the study. Three clients (Ms. A, Ms. B, and Ms. C) made large or relatively large improvements in their daily self-reported BDD symptoms during the ERP phase. A fourth client (Mr. D) did not make such an improvement during this phase, but made overall progress over the course of treatment. All four of these clients achieved statistically significant improvement over baseline on the standardized BDD measure. One client (Ms. E) dropped out of treatment during the ERP phase, and one (Ms. F) chose not to proceed to the ERP phase after receiving education about it. The results indicate that beneficial effects of treatment occurred during the ERP phase for three of the clients, and thus suggest that this component should, in spite of clients' almost reflexive, initial skepticism, be considered essential in the behavioral treatment of Body Dysmorphic Disorder. The variety of reactions of the different clients to the treatments is documented and discussed, along with an analysis of the factors that differentiated those clients who found the ERP phase helpful and those who did not.
\end{abstract}

Key words: Body Dysmorphic Disorder (BDD); Exposure and Response Prevention (ERP); behavioral therapy; case studies; clinical case studies; case series 


\section{CASE CONTEXT AND METHOD}

\section{Aim of the Study and Rationale for Selecting the Clients}

Body Dysmorphic Disorder (BDD) is characterized by a preoccupation with one or more imagined physical defects (American Psychiatric Association, 1994). It is a relatively common disorder, often with severe consequences for the individual (Phillips, McElroy, Keck, Pope, \& Hudson, 1993). The present study was driven by an interest in investigating the effect of exposure and response prevention (ERP) in relation to other components present in behavioral therapy for BDD. When initiating the study, there were six clients awaiting psychological treatment for BDD at an outpatient clinic and they were all recruited for the study. No clients were excluded. They were typical referrals to the clinic with co-morbidity and histories of previous treatments.

\section{The Clinical Setting in Which the Treatments Took Place}

The clients were treated within the Anxiety Unit at the outpatient clinic at Karolinska Hospital in Stockholm, Sweden. The unit specializes in pharmacological and cognitivebehavioral treatment of obsessive-compulsive disorder (OCD) and BDD. Clients are referred to the clinic from other psychiatric clinics in the Stockholm area. The clinic is a public treatment facility. Visitor fees function on a sliding scale, with a minimum of $\$ 1.00$ per visit and a maximum of $\$ 15.00$ per year. Undergraduate students from the clinical psychology program at Stockholm University frequently work as co-therapists at the unit. Two master students in psychology (one female and one male; see Table 2) specializing in Cognitive Behavioral Therapy (CBT) conducted the treatments in this study. The students received special training in CBT for BDD and supervision from the first author to ensure adherence to the study procedures and the ERP treatment principles.

\section{Method: The Single Case Design}

Single case study design has been viewed as one preliminary way of investigating mechanisms of change, before conducting larger scale group design studies of the overall efficacy of treatments (Kazdin, 1982; Barlow \& Nock, 2008). We used a single case design to study the impact of the ERP intervention when added to a therapeutic regime based on selfmonitoring and supportive therapy. As described below, the design consisted of four consecutive phases. The methodology employs repeated measurements over the course of the investigation to control for normal variation of the measured behavior. A single case design serves the aim of this study because important facets of therapeutic change could be investigated with a restricted number of clients, and no clients had to be randomized to a control group as every client served as his or her own control.

\section{Procedure}

Clients were assessed with a structured diagnostic interview, the Mini-International Neuropsychiatric Interview (MINI; Sheehan et al., 1998) by a senior psychiatrist. The clients that met the criteria for BDD according to the DSM-IV-TR (American Psychiatric Association, 1994) 
The Exposure and Response Prevention in the Treatment of Body Dysmorphic Disorder-A Case Series

F. Folke, M. Von Bahr, V. Assadi-Talaremi, \& J. Ramnerö

Pragmatic Case Studies in Psychotherapy, http://pcsp.libraries.rutgers.edu

Volume 8, Module 4, Article 2, pp. 255-287, 12-21-12 [copyright by authors]

as their main diagnosis were offered psychological treatment. They were assigned to one of the two therapists (one female and one male; see Table 2) based on the date of their referral. No special considerations were taken to age or gender. The treatment consisted of the following four consecutive phases.

UUPhase $\mathrm{A}_{1}$ consisted of one face-to-face session with a therapist and three weeks of baseline self-monitoring. This phase was initiated at the first visit to the therapist at the clinic. During this session, clients were given verbal and written information about the treatment process. An assessment interview for BDD-symptoms and the self-rating scales were administered. The patients were also taught how to complete a self-report diary and instructed to mail it to the clinic. Clients were only contacted by phone once a week in order to improve selfmonitoring adherence. Phase $\mathrm{A}_{1}$ ended with the therapist administering the self-rating scales.

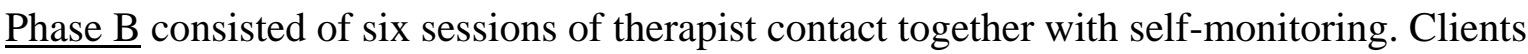
had scheduled appointments with the therapist twice a week. The aim was to help the client reflect upon the most recent days of their continued self-monitoring. The therapist provided interest, empathy, and information about BDD-symptoms but refrained from giving information about ERP. Phase B ended with the client filling out the same self-rating scales.

Phase C consisted of 14 sessions of ERP plus self-monitoring. This phase included education about BDD and the ERP model. Sessions continued on a twice-weekly schedule. Assessment and treatment planning sessions were conducted at the clinic, while exposure sessions were held either at the clinic or in the outside situations included by the clients in their fear-and-avoidance hierarchies (e.g., in schools, public places, and shopping malls). The last few treatment sessions were aimed at designing a relapse prevention plan. Phase C included continued self-monitoring and ended with the therapist administering a BDD-symptom interview and self-rating scales.

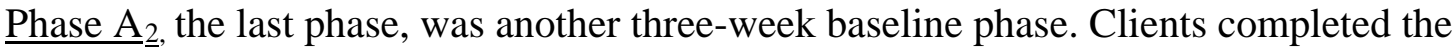
self-monitoring diary on their own and no therapist contact was planned during this phase.

A follow-up session was scheduled four weeks after the completion of Phase $A_{2}$. The clinical interview and self-rating scales were administered by the therapist. After this session, the clients were scheduled for continued medical and/or psychological support at the clinic, or they were referred back to their primary psychiatric clinic.

\section{Measures}

A number of standardized interviews and self-report scales are used in the clinic's routine assessment practice. In this paper we only report the three most relevant instruments used for measuring symptoms and outcome.

The Body Dysmorphic Disorder Modification of the Yale-Brown Obsessive-Compulsive Inventory Scale (BDD-YBOCS; Phillips et al., 1997) is a clinician-administered, semi-structured interview that assesses the severity of the past week's BDD symptoms. The BDD-YBOCS was administered at baseline (pre), post-phase $C$, and at follow up (post-phase $A_{2}$ ). The interview consists of 12 items. Five items assess BDD-related thoughts (obsessions), and five items assess 
The Exposure and Response Prevention in the Treatment of Body Dysmorphic Disorder-A Case Series F. Folke, M. Von Bahr, V. Assadi-Talaremi, \& J. Ramnerö

Pragmatic Case Studies in Psychotherapy, http://pcsp.libraries.rutgers.edu

Volume 8, Module 4, Article 2, pp. 255-287, 12-21-12 [copyright by authors]

BDD-related behaviors (compulsions). This instrument also rates the client's degree of insight and avoidance. Scores range from 0 to 48. The psychometric properties have been found adequate, with a test-retest reliability of .88 and a homogeneity (Cronbach's alpha) of .80. The scale was found to be sensitive to change in a study of fluvoxamine treatment. Mean baseline score was 31.1. ( $\mathrm{SD}=5.4)$, with a mean endpoint score of $16.9(\mathrm{SD}=11.8)$ (Phillips, Dwight, \& McElroy, 1998). Further empirically derived norms have not been identified, but Philips (2005) provides clinically-derived cut-off points for total scores on the BDD-YBOCS. Specifically, scores above 20 indicate current BDD; scores above 24 are considered moderate; scores in the 30 s designate moderate to severe BDD; and, a score in the 40s indicate very severe BDD.

The Sheehan Disability Scale (Sheehan, Harnett-Sheehan, \& Raj, 1996) is a three-item, self-report scale used to assess functioning in three areas of life (work, social life, and family life). Each item is rated on an 11-point Likert-type scale ranging from zero (no impairment) to 10 (extreme impairment), while the total range extends from zero to 30 points. High internal consistency has been reported with a coefficient alpha of .89 (Leon, Olfsson, Portera, Farber, \& Sheehan, 2007). Test-retest reliability estimates have not been identified for this scale. Sheehan and Sheehan (2008) reported mean total scores for a number of diagnostic groups, ranging from 23.1 for depression to 14.2 for generalized anxiety disorder. These authors also found the instrument sensitive to treatment changes, but no data on non-clinical samples were provided. In a sample of outpatients with obsessive-compulsive disorder $(n=70)$, mean pre-treatment scores of 18.91 and mean post-treatment scores of 10.64 were reported (Diefenbach, Abramowitz, Norberg, \& Tolin, 2007)

The MADRS-S. A self-assessment version (Svanborg \& Åsberg, 1994) of the Montgomery-Åsberg Depression Rating Scale (MADRS-S; Montgomery \& Åsberg, 1979), was used to measure depressive symptoms. The MADRS-S was administered at baseline (pre) and at each phase transition (i.e., post-A1, post-B, post-C, and post-A2). It contains nine items that capture different aspects of depression. Each item is rated by clients on a scale ranging from zero to three, with the possibility of half-steps. The total range extends from zero to 27 points. (Note that the MADRS-S is sometimes rated on a zero to six with no half-steps, e.g., Svanborg \& Ekselius [2003]. The scale has been reported to possess good psychometric properties, with a test-retest reliability of .78 and an internal consistency (Cronbach's alpha) of .84 (Fantino \& Moore, 2009). Svanborg and Åsberg (2001) reported a mean score of 14.5 (SD=4.7) for patients with a diagnosis of major depression, whereas those in full remission had a mean score of 1.7 $(\mathrm{SD}=0.8)$. No clear-cut empirically derived cut-offs are available for MADRS-S.

The Reliable Change Index (RCI; Jacobson \& Truax, 1991) was calculated for each client in regard to change in total score on BDD-YBOCS and MADRS-S, from baseline (i.e., pre) assessment to consecutive assessment points. To get an approximate estimate of reliable change on the SDS, in spite of the lack of necessary psychometric data, we calculated the change index with .80 as an assumed value for the test-retest reliability.

For the continuous monitoring of BDD-related symptoms, a self-report diary was created. This diary included five items, which the clients rated on a scale of zero to eight once a day (i.e., one overall rating on each item per day). The items were: (1) "Rate the amount of time you have had obsessions related to appearance during the day," (2) "How distressed were you by the 
obsessions?" (3) "Rate the amount of time you have spent on compulsions related to appearance during the day," (4) "Rate how able you were to control the compulsions," and (5) "Rate your degree of avoidance due to appearance concerns during the day.” To achieve a single compound core indicator on this measure, a daily mean score was calculated for every client. Clients received training in completing the diary card during the first meeting with the therapist, using the past week as an example. Problem-solving was used to come up with ideas on how to improve adherence to self-monitoring (e.g., keeping the diary cards within sight, using reminders, and creating routines). The clients were given diary cards that would last until the next meeting at each session. As there was only one face-to-face session in the three weeks during phase $A_{1}$ and during phase $A_{2}$, clients were instructed to mail their diary cards to the clinic each week (to ensure adherence) and they were phoned once a week to see if they had questions and to remind them about the diary cards. In phases B and C, clients came to the clinic twice a week and were instead instructed to bring the diary cards to each session.

The daily compound ratings were used to graphically display treatment progress over the consecutive treatment phases (see Figure 1). To get a rough estimate of change beyond that provided by visual inspection alone, standardized change scores (SCSs) were calculated. Each client's mean score in every treatment phase $\left(\mathrm{M}_{\mathrm{x}}\right)$ was compared to the mean score of the selfmonitoring phase $\left(\mathrm{M}_{\mathrm{A} 1}\right)$, taking into account the standard deviation $\left(\mathrm{SD}_{\mathrm{A} 1}\right)$ of this phase $\left.\left(\mathrm{M}_{\mathrm{x}}-\mathrm{M}_{\mathrm{A} 1}\right) / \mathrm{Sd}_{\mathrm{A} 1}\right)$. These scores are provided in Figure 1.

\section{Confidentiality}

Clients were informed of the purpose of the study and that in agreeing to participate they would receive the standard assessment and treatment at the clinic, except they would benefit from more intense therapist contact than was usual. They were informed that data stripped from personally identifiable information might be published. Clients were also told that participation in the study was voluntary and that refusing would not affect their treatment at the clinic. All clients gave their verbal consent for their data to be used in this clinical evaluation.

\section{THE CLIENTS}

The clients were relatively young and all but one was female (relevant demographical and clinical data regarding the clients are displayed in Table 1). All of them were either students or employed, but they all had significant problems in occupational or social functioning due to BDD. Two clients (Ms. B and Ms. F) were practically housebound and had been so for some time. On the BDD-YBOCS scores at the beginning of treatment, as shown in Table 3, two clients (Ms. A and Ms. B) scored in the range of very severe BDD; two (Ms. C and Ms. F) scored in the moderate to severe range; and two (Mr. D and Ms. E) scored in the moderate range at intake (see Table 3). The clients reported physical concerns about their face, skin, and hair. Half of the clients used prescribed anti-depressant medication on a stable dose. All clients were diagnosed with co-morbid depression. The onset of the disorder was generally reported during early adolescence. The clients reported that most of the time they were convinced about an actual flawed appearance, and they expressed different levels of reluctance towards psychological treatment at pre-assessment. From a clinical point of view, the clients in this study were in many instances typical of BBD-clients on the severe end of the clinical spectrum. 


\section{GUIDING CONCEPTION WITH RESEARCH AND CLINICAL EXPERIENCE SUPPORT}

\section{Body Dysmorphic Disorder}

BDD is a disorder that is characterized by a preoccupation with an imagined or slight defect in appearance (APA, 1994). It is also a disorder that can be associated with severe impairment (DeMarco, Li, Phillips, \& McElroy, 1998; Phillips, McElroy, Keck, Pope, \& Hudson, 1993). Also BDD is, in many cases, associated with a chronic course (Phillips \& Diaz, 1997; Phillips, Menard, Fay, \& Weisberg, 2005c); alarming rates of suicide attempts and suicidal ideation (Phillips et al., 2005a); and impaired quality of life (Phillips, 2000; Phillips, Menard, Fay, \& Pagano, 2005b). Individuals with BDD tend to have poor insight (Phillips, Menard, Pagano, Fay, \& Stout, 2006) and reluctance to engage in treatment is not uncommon (Buhlmann, Reese, Renaud, \& Wilhelm, 2008). In the last two decades, successful treatments for BDD have emerged and medical treatment with anti-depressants and psychological treatment with CBT are currently considered first line treatment for BDD (National Collaborating Centre for Mental Health, 2005).

\section{Behavioral Theory and Therapy of Body Dysmorphic Disorder}

Learning theory accounts have previously been provided for the development, maintenance, and treatment of a vast range of different disorders (e.g., Sturmey, 1996). These behavioral principles have been applied to propose a clinical model for BDD (Rabinowitz, Neziroglu, \& Roberts, 2007). In this model, it is hypothesized that some individuals carry a genetic predisposition, which in combination with early learning experiences, constitute the basis for BDD. The contribution of two major behavioral processes is emphasized regarding the development and maintenance of the symptoms of BDD: respondent and operant conditioning.

Respondent conditioning is present in the process whereby previously neutral stimuli acquire aversive functions by association with stimuli that intrinsically evoke negative affect. In BDD the presence of some physical feature will acquire anxiety-eliciting functions as a result of having been associated with events like being teased or bullied.

Operant conditioning is the process whereby certain behaviors in certain contexts are reinforced and thus are made likelier to be repeated, while other behaviors are extinguished or punished. Operant principles can be used to understand the compulsive behaviors observed in BDD. Compulsive behaviors may function to reduce contact with stimuli that evoke distress or to reduce the experience of anxiety itself. When a person with BDD successfully reduces experienced anxiety by, for example, compulsively checking his nose in the mirror, this checking behavior is negatively reinforced by anxiety reduction. This happens despite the fact that this behavior carries with it considerable increased long-term costs for the individual, with regards to time consumption and increased effort. Individuals with BDD often avoid situations that remind them of their perceived flaw and this prohibits them from participating in new learning experiences. 
Based on the assumption that the obsessions and compulsions in BDD are functionally similar to those in OCD, the treatment principle of exposure and response prevention (ERP) has been applied to BDD too. This approach aims to encourage the client to confront the feared event in a graded fashion (i.e., exposure) for as long it takes for anxiety subside and thereby extinguish the aversive and avoidance-evoking functions of the event. In the case of BDD, this often means being in public places and talking to others while not hiding the perceived flaws in appearance. Response prevention in BDD usually implies abstaining from checking, asking for reassurance, seeking out dermatologists, performing cumbersome make-up rituals, skin picking, and so forth.

The process of ERP treatment starts with a thorough assessment of the client's thoughts, feelings, and behaviors as related to their BDD. A case conceptualization focusing on the analysis of functional relations between relevant contextual factors and the problematic behavior is carried out and shared with the client. A treatment plan is created collaboratively, containing a fear and avoidance hierarchy, a response-prevention plan, and explicit goals for treatment. The majority of time in therapy is spent on exposure in feared situations. The last sessions are devoted to reviewing the therapy process and progress towards the treatment goals, and to creating a relapse-prevention plan. Throughout therapy the therapist is trying to adopt a therapeutic stance based on educational and motivational verbal interventions to increase client engagement in treatment.

Concerning empirical data documenting the process and effectiveness of the use of CBT in treating BDD, a review by Greenberg and Wilhelm (2011) concludes that

the literature is sparse but promising. Evidence suggests that CBT for BDD is associated with symptom improvement, generally performs better than wait-list controls, and is associated with improvement in associated features, including functioning, depression, anxiety, and delusional beliefs. However, the small number of studies and methodological limitations hamper definitive conclusions about the efficacy of CBT for BDD (p. 349).

Relatively few systematic case studies of behavior therapy with BDD disorders have been published. A notable exception is Greenberg et al.'s (2010) description of the successful treatment of "Marcy," a 17-year-old year old high school student in the United States with diagnoses of primary BDD and current, comorbid obsessive-compulsive disorder, conduct disorder, and attention-deficit/hyperactivity disorder. In addition to ERP, Marcy's 12-session treatment included parent training, cognitive strategies, and skills training. 


\title{
4-7 ${ }^{1}$. CASE INFORMATION, COURSE OF TREATMENT, AND THERAPY MONITORING FOR THE CLIENTS
}

\author{
Client 1: Ms. A
}

\section{a. Presenting Problem}

Ms. A was a 24-year-old university student living alone. She was diagnosed with BDD, concurrent major depression, and generalized social phobia. Ms. A studied at the University but avoided situations like social interactions, classmates, most campus areas, and shopping malls. At the time of assessment, she would not leave home without extensive make-up rituals. Ratings on standardized measures indicated very severe BDD, marked depression, and problems in global functioning (on the Sheehan Disability Scale [SDS]) at pre-assessment (Table 3).

\section{b. History}

Ms. A reported being bullied in middle school. During this period she became dissatisfied with her appearance and started to avoid social situations. She described her adolescence as very traumatic and the traumas were events and experiences related to appearance. Ms. A had no previous experience of regular psychotherapy of any kind. Shortly before her treatment at our clinic, she went to a couple of sessions with a counselor. She was on a stable dose of antidepressant medication when she began treatment.

\section{c. Assessment of Thoughts, Feelings, and Behaviors as Related to the Client's BDD}

Ms. A experienced her face to be disfigured. She was certain that the disfigurement was visible to others, despite reassurance from many. She experienced intense feelings of anxiety and shame when exposed to others' attention and avoided any situation that could result in people looking at her face. She often spent hours in front of the mirror to try and hide the perceived disfigurement with make-up and fantasized repeatedly about surgical corrections.

\section{d. Individualized Case Formulation}

Ms. A's experiences with bullying may account via respondent conditioning for the development of her fear and shame reactions to certain triggers, e.g., others looking at her and mirror images. Merely thinking about her face elicited intense feelings of fear, disgust, and anxiety. Her make-up rituals had become more and more time-consuming and ritualistic the past years, and adhering to her make-up ritual was the only strategy she had that made her comfortable enough to go out in public, i.e., her ritualistic make-up behavior was negatively reinforced. The avoidance of social interactions had generalized to more situations over the years. She could easily relate to both rituals and avoidance as being anxiety-reducing in the short-term but counterproductive in the long-run as such behaviors made her more preoccupied

\footnotetext{
${ }^{1}$ This section is numbered "4-7" to indicate its parallel to sections 4-7 of a typical PCSP case studyspecifically: 4) Assessment of the Client's Problems, Goals, Strengths, and History; 5) Formulation and Treatment Plan; 6) Course of Therapy; and 7) Therapy Monitoring and Use of Feedback Information.
} 
The Exposure and Response Prevention in the Treatment of Body Dysmorphic Disorder-A Case Series

with her appearance and more distressed when she had to face social situations.

\section{e. Individualized Treatment Plan for ERP}

Ms. A's goal for therapy was becoming able to participate in social situations, make contact with people, and not have to prepare for hours before leaving her home. Her fear-andavoidance hierarchy contained a number of items, including walking the clinic hallway and hospital area with no make-up on (the least fear/shame evoking); visiting public areas without make-up (moderately fear/shame evoking); going to the university campus (strongly fear/shame evoking); and eating in the campus restaurant without make-up on (extremely fear/shame evoking). A response prevention plan was collaboratively developed including restricting the use of mirrors both at home and at the university, and to abstain from wearing make-up in the critical situations during ERP practice.

\section{$\underline{\text { f. Course of Treatment }}$}

Ms. A was treated by the male psychology masters student (see Table 2). During Phase $\mathrm{A}_{1}$, she was engaged in the process of self-monitoring. The instructions were well understood and followed. As therapist contact was provided in Phase B, this was positively experienced by the client as a chance to share information about her concerns and daily life with someone knowledgeable of BDD.

Early on in phase C, Ms. A expressed reluctance regarding the ERP method, but the therapist persisted and helped the client by grading exposure exercises even more than originally planned and by providing encouragement for every small step she agreed to take in the direction of exposure. During session two of the ERP phase, she walked around in the clinic hallways without make-up on. She was still worried about future exposures. However, as she acquired more experience, she learned she could master exposure exercises on her own. She exposed herself to numerous social situations without make-up on (e.g., sitting on the bus and walking in a mall while asking people questions). Eventually she confronted the highest ranked fear in her anxiety hierarchy: eating at a public restaurant without make-up. Ms. A repeated the exposures from the sessions as homework and had continued to do so at follow-up. At the end of treatment, Ms. A was without make-up for several days but planned to introduce it again at a restricted level.

\section{g. Response to Therapy}

After Phase C of treatment, Ms. A had made substantial progress as indicated by the BDDYBOCS. This score, initially in the very severe range, fell just below the clinical range after treatment. This change fulfilled criteria for reliable change on the Reliable Change Index (RCI = -6.33). Her depression score $(\mathrm{RCI}=-3.37)$ and SDS score $(\mathrm{RCI}=-4.08)$ also showed a substantial and reliable decrease after Phase $\mathrm{C}$.

Figure 1 reveals no marked improvements in BDD-symptoms, during the $\mathrm{A}_{1}$ and $\mathrm{B}$ phases. This lack of improvement is paralleled in the self-rating of depression and social functioning, as shown in Table 3. The patient was still constrained to only leaving her house with make-up on and was equally distressed by thoughts about her appearance. 
During Phase C, daily self-rated BDD symptoms instantly began a steady and gradual improvement achieving a large SCS of -2.63 (Figure 1). This improvement was also observed by the therapist and seemed to occur quite rapidly after Ms. A started conducting exposure on her own outside the clinic. She started looking forward to social situations and events in her life that she had avoided before. She began enjoying going to university classes and often stayed around the university campus after class.

During the follow-up session, Ms. A stated that she felt as though she had a new life and that she no longer was afraid of being around others. She commented that the treatment had been challenging, but she had learned how to better handle fear and anxiety. Ms. A said her most important learning experience was when she, at numerous times, discovered that anxiety decreased whenever she remained in a distressing situation. After treatment, she did not avoid situations, and none caused distress anywhere near the same levels as before.

\section{Client 2: Ms. B}

\section{a. Presenting Problem}

Ms. B was a 17-year-old girl living with her parents. She was diagnosed with BDD, concurrent major depression, and generalized social phobia. The main area of her appearance concern was the face. At the time of assessment, Ms. B had not been to school for more than a year and very seldom left home. She had one friend, but it was difficult for them to meet since Ms. B did not go anywhere. Ratings on standardized measures indicated very severe BDD, depression, and problems in global functioning at pre-assessment (Table 3).

\section{b. History}

Ms. B described her family relations as close and warm. At school she had been harassed and bullied, mainly because of her clothing style. During the therapy sessions, Ms. B also reported a general fear of people of her own age that emerged around the same time as the bullying. In her early teens she started to focus on her appearance and eventually started to cover her face and avoid social situations. Eventually she developed major depression. Ms. B was using a stable dose of antidepressant medications when she started therapy. She had no previous experience of regular psychotherapy of any kind.

\section{c. Assessment of Thoughts, Feelings, and Behaviors as Related to the Client's BDD}

Ms. B disliked everything about her face, especially her nose and skin. She believed she had a problem with acne and that others would be disgusted by the sight of her skin. She also thought her nose was disproportionately big and that her face was asymmetric. Ms. B stated that she thought she looked like a monster and did not want to scare other people by showing them her face. Therefore she hid her face with different clothing whenever she was away from home. She was afraid that her appearance would shock others and that they would look disgusted, turn away, or comment negatively on her appearance. People of her own age were especially fearevoking since she believed they would laugh or tease her. At the time of assessment Ms. B spent almost all her waking time in front of the mirror or online, reading about plastic surgery. When looking in the mirror she analyzed her appearance in different angles and lights. She spent a lot 
of time fantasizing and reading on the internet about making changes with plastic surgery or treating her skin with specialized products.

\section{$\underline{\text { d. Individualized Case Formulation }}$}

Via respondent conditioning, Ms. B had several learning experiences (e.g., harassment and bullying) that may account for the development of her emotional reactions (fear, shame, and disgust) to certain triggers, like people of her own age and images of herself in mirrors and photographs. Ms. B started to engage in mirror checking, camouflaging her face, and avoiding social situations as a way of coping with both the triggers themselves and her emotional reactions to them. These behaviors temporarily reduced anxiety and were therefore maintained via negative reinforcement. As her avoidance and compulsive behaviors continued, the preoccupation with her appearance grew worse and the aversive functions of certain stimuli generalized to anything remotely reminding her of her skin and nose, such as talking about school or being outside. In this vicious cycle her compulsions escalated, and finally she avoided almost every social situation.

\section{e. Individualized Treatment Plan for ERP}

Ms. B wanted to be able to show her face in public, and her main goal was to go back to school. She also wanted to be able to go to shopping malls and restaurants with her friend, using public transportation. Her fear-and-avoidance hierarchy contained a number of items, including showing her face to the therapist (the least fear/shame evoking); walking around in the hospital area (moderately fear/shame evoking); appearing with her face visible in malls, cafés, and the subway (strongly fear/shame evoking); and seeking out and talking to strangers of her own age (extremely fear/shame evoking). A response prevention plan was collaboratively construed with the purpose of gradually decreasing the time spent in front of the mirror as well as the time online reading about surgery and skin treatment.

\section{$\underline{\text { f. Course of Treatment }}$}

Ms. B was treated by the female psychology masters student (see Table 2). During Phase $\mathrm{A}_{1}$, she self-monitored her symptoms on a daily basis. In the beginning of Phase $\mathrm{B}$, it appeared to be very distressing for her to talk about her problems with the therapist and she was reluctant to look at the therapist. Throughout this phase, she covered her face even in the therapist's office.

Regarding Phase C, Ms. B was initially reluctant to try ERP; but after assessing the consequences of giving versus not giving ERP a chance and after including less distressing situations in the hierarchy, she was willing to consider ERP. Her first exposure exercise in Phase $\mathrm{C}$ was to show her face to the therapist. The next step consisted of her walking around the hospital area with her face fully visible, and gradually she was introduced to asking people questions during these walks. After the first exposure exercises, Ms. B felt encouraged. She started looking more at the therapist and expressed herself more openly. She stated that others did not react with disgust and that she managed to do more than she had hoped for. This motivated her to try new exposure exercises. Her exposure exercises progressed to appearing with her face visible in malls, cafés, the subway, and other places where you often meet people 
of her own age. Towards the end of this phase, Ms. B used exposure exercises creatively, trying to draw attention to herself in stores by talking loudly or by tripping on purpose.

When Ms. B was first introduced to the response prevention rationale, she doubted that restricting the time she spent in front of the mirror would result in her thinking less about her appearance, but gradually she discovered this to be the case. As abstaining from mirror-checking was very challenging to Ms. B, she was encouraged by the therapist to come up with alternative activities that were non-compatible with this ritual (e.g., playing computer games).

During Phase $\mathrm{A}_{2}$, Ms. B continued the exposure exercises on her own by showing her face in public areas while continuing to reduce her rituals.

\section{g. Response to Therapy}

After Phase C of treatment, Ms. B had made substantial progress as indicated by the BDDYBOCS. This score, initially in the very severe range, fell just below the clinical range after treatment. This change fulfilled criteria for reliable change (RCI= -7.47). Her depression score showed a substantial and reliable decrease (RCI= -2.89) after phase B and improved further after Phase C. Her SDS global functioning score improved reliably $(\mathrm{RCI}=-4.69)$ after Phase C.

The graph in Figure 1 indicates no improvements in BDD symptoms during Phases $\mathrm{A}_{1}$ or B. Neither was any improvement in functioning observed (Table 3). These observations were in accordance with clinical observation. During Phase C, self-rated BDD symptoms showed a steady but gradual improvement with a relatively large SCS value of -1.19 (Figure 1). As Ms. B's BDD improved she became more active and outgoing and as a result, as she described, she had less time and motivation for adhering to the self-rating procedure. Verbal reports of improvement from the client and her family paralleled the self-ratings. Ms. B described the treatment as an extremely helpful and life-changing experience. She was able to go to school and spend time with her friend, doing things they were not able to do prior to the treatment, such as to shop for clothes and to eat at restaurants. Ms. B almost completely stopped spending time in front of the mirror and reading about plastic surgery. She thought the most important thing she discovered in the treatment was that she was able to expose her face without causing fear in others. Instead of spending most of her time in front of the mirror, she now felt that she could engage in meaningful activities and enjoy life.

\section{Client 3: Ms. C}

\section{a. Presenting Problem}

Ms. C was a 32-year-old student. She was single, living alone, and had a limited number of close friends. She was diagnosed with BDD and concurrent major depression. Her concerns over her appearance had an especially large impact on her social life; she avoided meeting friends and became very distressed in public places, such as restaurants and nightclubs. It was also an obstacle for her meeting a romantic partner, which was something she missed deeply. Ratings on standardized measures indicated severe BDD and marked depression (Table 3). 
The Exposure and Response Prevention in the Treatment of Body Dysmorphic Disorder-A Case Series

\section{b. History}

Ms. C grew up with her mother, father, and younger sister. Ms. C had no former experience of regular psychotherapy. However, prior to treatment, Ms. C underwent counseling with a psychiatric nurse for about a year, focusing mainly on her depression. She had also tried antidepressant medication for several years, but she reported none of these treatments had any positive effect. Ms. C continued medicating during the treatment at our clinic.

\section{c. Assessment of Thoughts, Feelings, and Behaviors as Related to the Client's BDD}

Ms. C was mainly concerned with her facial skin and would never leave home with less than perfect make-up. She believed she had a problem with acne and therefore tried to find products to treat her skin and wanted to cover the acne with make-up. She avoided getting warm due to the fear of ruining her make-up, and regularly checked mirrors to ensure she looked perfect. She felt ashamed of her skin and was afraid of others' reactions. When spending time with friends, she made comparisons and felt uncomfortable showing her face in certain lights.

\section{d. Individualized Case Formulation}

Ms. C recalls often getting attention for her looks during childhood. In her family she was appreciated for being pretty (i.e., positively reinforced for appearance-related activities). In her late teens, Ms. C gained weight and developed a minor problem with acne. As this happened, her skin, and anything reminding her of it, became associated with feelings of shame. Instead of focusing on her pretty features, she now began scrutinizing her skin in an obsessive way. Via negative reinforcement, checking and scrutinizing her appearance in mirrors served the function of anxiety reduction. However, at the same time, this checking triggered her feelings of shame and fear and motivated further attempts at camouflaging her perceived flaws with make-up.

\section{e. Individualized Treatment Plan for ERP}

Ms. C stated that her main goal for therapy was becoming more spontaneous, and this required her being able to leave home without hours of preparation. Her fear-and-avoidance hierarchy contained a number of items, including not wearing make-up with the therapist (least anxiety evoking); not wearing make up in public places while posing questions to strangers (moderately anxiety evoking); and wearing no or less make-up at restaurants and bars talking to potential partners (extremely anxiety evoking). A response prevention plan was collaboratively developed with the purpose of reducing the preparation time before leaving home, spending less time in front of the mirror, and using fewer skin products.

\section{$\underline{\text { f. Course of Treatment }}$}

Ms. C was treated by the female psychology masters student (Table 2). During Phase $A_{1}$, Ms. $C$ was engaged in the process self-monitoring. The instructions were well understood and followed. When meeting with the therapist during Phase B, Ms. C was able to express her appearance concerns and how it affected her life, and she expressed appreciation at being taken seriously and having someone who understood that her concerns over her appearance constituted a major issue for her. 
In Phase C, Ms. C's exposure exercises began by showing her face to the therapist without wearing make-up, and later on going to shopping malls where she asked people questions and tried on clothes without wearing make-up. Ms. C was motivated to do her exposure exercises and often pushed herself to the next step. At first, Ms. C was reluctant to decrease her rituals as she was concerned it would negatively influence her appearance. When helped to further identify the short-term consequences (anxiety reduction) and long-term consequences (increased concerns over appearance) of her extensive rituals, she was able to successfully decrease them.

\section{g. Response to Therapy}

After the Phase $\mathrm{C}$ of treatment, Ms. $\mathrm{C}$ had made a substantial progress as indicated by the BDD-YBOCS. This score, initially in the moderate to severe range, fell well below the clinical range after treatment. This change fulfilled criteria for reliable change $(\mathrm{RCI}=-6.33)$. Her depression score also showed a substantial and reliable decrease after Phase C (RCI = -3.85). Her SDS score, on the other hand, indicated deterioration after phase $A_{1}(\mathrm{RCI}=1.84)$ and after Phase $B$ this increase in rated disability was statistically significant $(\mathrm{RCI}=2.04)$. Eventually, after Phase $\mathrm{C}$ her SDS score was one point away from achieving a reliable improvement as compared to the baseline score $(\mathrm{RCI}=-1.84)$.

The self-ratings (Figure 1) and client verbal reports indicated no marked improvements in BDD-symptoms during Phases $\mathrm{A}_{1}$ or $\mathrm{B}$. The variability in self-ratings was explained by the client as depending on the fact that she experienced fewer symptoms on days that she studied at home. Ms. C did describe feeling less depressed after therapist contact was initiated in Phase B, and this parallels a modest improvement in her self-rated depression (Table 3). Ms. C reported that she continued to avoid public venues and situations and that she remained preoccupied with rituals at about the same extent during Phases $\mathrm{A}_{1}$ and $\mathrm{B}$. This avoidance and preoccupation is further indicated by her SDS scores during these phases.

During Phase C, a relatively large improvement was noted regarding the self-monitored BDD symptoms, with an SCS score of -1.31 (Figure 1). When Ms. C reduced her compulsive behavior, she reported that she found herself thinking less about her appearance. She described the exposure exercises as being very helpful and not as hard as she had expected. She enjoyed doing things she had avoided for so long and sometimes felt sad she did not know earlier that this was such an effective way of dealing with her problem. Towards the end of Phase C, she even initiated contact with men and went on dates. Assessments of depression at the end of Phase $\mathrm{C}$ indicated that these areas had improved reliably and assessments of functioning bordered reliable improvement. Follow-up data was not collected from this client. At the end of Phase $A_{2}$, Ms. C described that she felt free when she was not bound to wearing make-up. She now appreciated spending time with friends and focused on their conversations rather than hiding her face, and she also appreciated her ability to be more spontaneous in public situations. 


\section{Client 4: Mr. D}

\section{a. Presenting Problem}

Mr. D was a 20-year-old male high school student living with one of his parents. He was diagnosed with BDD, concurrent major depression, and generalized social phobia. His primary concern was with the appearance of his skin and nose. This concern interfered with his daily life in many ways as he avoided most social situations. Mr. D still managed to go to school but he often skipped class due to his preoccupation with his appearance. At pre-assessment (Table 3), Mr. D's standardized measures indicated moderate BDD, depression, and problems in global functioning (Table 3).

\section{b. History}

Mr. D had a history of anorexia in his early teens. At pre-assessment he no longer fulfilled the diagnostic criteria for anorexia nervosa and both his weight and eating habits were normal. One year prior to the current treatment, he had undergone a couple of months of CBT. This treatment was reported to have been somewhat successful, but the improvement had since deteriorated. However, this meant the client did have some theoretical knowledge, as well as personal experience of the treatment model. Mr. D also had a previous experience with supportive therapy that he received as part of treatment for his eating disorder.

\section{c. Assessment of Thoughts, Feelings, and Behaviors as related to the Client's BDD}

Mr. D had recurring, intrusive thoughts about his skin and nose. These thoughts got worse when he attempted eating in public places, going to parties, shopping in malls, or going on dates. His emotional reactions included fear, disgust, and shame. Most of the time Mr. D avoided such situations, and he was frequently engaged in time-consuming rituals (e.g., mirror-checking and using skin products). Mr. D thought his looks would make it impossible for him to date and find a partner.

\section{d. Individualized Case Formulation}

For as long as Mr. D could remember, he had been preoccupied with different aspects of his appearance. His concerns would easily generalize from one bodily area to another in that thoughts of one body area triggered uncertainty regarding other body features. His current concerns emerged at the onset of puberty when he developed acne and his nose changed somewhat and the related anxiety was triggered by anything reminding him of his concerns (e.g., other people, school, and mirrors).

Mr. D reported he had always used avoidance and rituals as coping strategies, both when he had had an eating disorder and when he had later developed BDD. It was evident to him that rituals served a short-term, distress- relieving function (i.e., negative reinforcement). In the long run, however, he had noticed that the rituals made him more uncertain and critical of his appearance, more attentive to others' negative reactions to him, and more prone to explain his failures (especially regarding dating) in terms of having to do with appearance. 
The Exposure and Response Prevention in the Treatment of Body Dysmorphic Disorder-A Case Series

F. Folke, M. Von Bahr, V. Assadi-Talaremi, \& J. Ramnerö

Pragmatic Case Studies in Psychotherapy, http://pcsp.libraries.rutgers.edu

Volume 8, Module 4, Article 2, pp. 255-287, 12-21-12 [copyright by authors]

\section{e. Individualized Treatment Plan for ERP}

Mr. D’s goals for therapy included increasing both his close relationships (e.g., by dating) and ability to be in public spaces. His fear-and-avoidance hierarchy contained a number of items, including showing his face in bright light for close persons (the least fear evoking); being fully visible in public places (moderately fear evoking); going to public baths and posing questions to people in the street (strongly fear evoking); and dating (extremely fear evoking). A response prevention plan was collaboratively constructed including restricting the use of mirrors and reducing time spent on skin care.

\section{f. Course of Treatment}

Mr. D was treated by the male psychology masters student (Table 2). During Phase $\mathrm{A}_{1}, \mathrm{Mr}$. D. was engaged in the process self-monitoring. The instructions were well understood and followed. When therapist contact was added in Phase B, Mr. D experienced this as somewhat distressing (as he had to sit face-to-face with the therapist) but mainly emotionally supportive.

During Phase C, Mr. D participated willingly and engaged in exposure exercises, such as exposing his face to bright lighting in the presence of the therapist, posing questions to people in the street, and eating at restaurants and swimming at public baths. His homework assignments during this phase included approaching dating situations and eventually going on a date. Mr. D also cut down on skin care rituals but did not manage to reduce the time spent in front of the mirror.

However, later on during Phase C, Mr. D experienced a major setback when he became ill with an infection that affected his skin. As a result his obsessions became more intense. This changed the situation significantly for the client, not least of which was the expected adversity of the remaining feared events targeted in therapy. Together, Mr. D and his therapist chose to start over from the beginning of his fear and avoidance hierarchy. Mr. D did continue with ERP exercises on his own during phase $\mathrm{A}_{2}$, and reported significant progress when he came in for the follow-up assessment.

\section{g. Response to Therapy}

Mr. D’s BDD-YBOCS score, initially in the moderate range, fell just below the clinical range after Phase $\mathrm{C}$ and well below at follow up. The reduction in score to follow-up fulfilled criteria for reliable change (RCI = -2.59). Mr. D's depression (i.e., MADRS-S score) did vary to some degree between phases but no reliable change was achieved. His SDS score indicated reliably decreasing disability after phase B $(\mathrm{RCI}=-2.45)$, returned to base line levels after Phase $\mathrm{C}$, and improved reliably again at follow-up.

As shown in Figure 1, self-rated BDD symptoms were relatively stable during Phases $\mathrm{A}_{1}$ and $\mathrm{B}$ but somewhat intensified during Phase C. The client attributed this increase of BDD symptoms to the infection he developed during Phase C. Despite this, he began to engage in activities he desired to do, such as going on a date. He also stopped engaging in different avoidance behaviors (e.g., sitting at a fixed place on the bus or in the classroom), and rituals (e.g., picking special clothes to conceal certain body parts). From a clinical point of view, this 
The Exposure and Response Prevention in the Treatment of Body Dysmorphic Disorder-A Case Series

picture of intensified BDD symptoms was not unequivocally synonymous with deterioration. In fact, the client verbally reported increased self-esteem during Phase C. Mr. D’s verbal reports of decreased avoidance were however contradicted by his self-reported SDS functioning scores that indicated a return to baseline functioning. During Phase $\mathrm{A}_{2}, \mathrm{Mr}$. D did not return any daily selfratings as he experienced it to be too much work. At the follow-up session, Mr. D said he learned how ERP works and how to apply it to his life. He was worried about the ups-and-downs, but more confident that he could handle the setbacks, and could also very clearly see the progress he had made during the process of therapy.

\section{Client 5: Ms. E}

\section{a. Presenting Problem}

Ms. E was a 35-year-old woman living with her partner. She was diagnosed with BDD and concurrent major depression. Her main areas of concern were her facial skin, facial hair, and hair. She worked full-time but experienced her life to be severely impaired by BDD. Ratings on standardized measures indicated moderate BDD, marked depression, and problems in global functioning at pre-assessment (Table 3).

\section{b. History}

Ms. E’s preoccupation with her physical appearance began six years prior to treatment when she started worrying about her hair. After developing a minor skin pigment change, she became very concerned with this. Ms. E had a history of bulimia in early adulthood, but at the time of assessment she was no longer binge eating or purging. She had attended a psychodynamic therapy for BDD for six years. She reported that it had had very limited effects, if any, regarding her appearance concerns.

\section{c. Assessment of Thoughts, Feelings, and Behaviors as Related to the Client's BDD}

Ms. E stated that her life would have been wonderful if it had not been for her preoccupation with her facial skin, facial hair, and hair loss. She engaged in various timeconsuming rituals that caused significant distress, and she was prone to ruminate intensely over how she had developed her perceived appearance problems and how she could prevent them from becoming worse.

\section{d. Individualized Case Formulation}

Ms. E had been concerned with appearance, and she had been prone to use avoidance strategies to regulate emotional reactions (e.g., binge eating and ruminating) prior to developing BDD. She had noticed that her attentiveness to appearance easily generalized from one area (e.g., hair) to another (e.g., skin). Her anxiety and distress was triggered in a broad range of situations (e.g., mirror images, pictures of beautiful people, talking about appearance, or talking about the future).

Ms. E recognized that her concerns were being maintained by her short-term anxietyreducing rituals (e.g., combing and mirror-checking). However, her most frequent and 
problematic ritual was covert, consisting of her ruminative thinking about why she had developed the skin and hair problems. She experienced rumination as part of a problem solving strategy (e.g., "If I could figure out how I got here maybe I could find my way out") that she felt compelled to use despite the fact that it had never been experienced as effective. In a vicious cycle, Ms. E tried to avoid mirrors and talking to her family about her problems in order to avoid evoking uncertainty, while at the same time she did turn to mirrors and family members to gain reassurance, in turn evoking the uncertainty she was trying to avoid.

\section{e. Individualized Treatment Plan for ERP}

Ms. E’s goal with therapy was spending less time ruminating about her appearance and being more attentive to her relationships than to her appearance. Her fear-and-avoidance hierarchy contained a number of items, including approaching mirrors without ruminating (least fear evoking); ruffling her hair (moderately fear evoking); and going to work without camouflaging her perceived skin condition (strongly fear evoking). A response prevention plan was collaboratively developed and included restricting the use of mirrors for reassurance seeking and reducing time spent on skin care. She was also encouraged to list alternative activities to rumination in order to try them out, in particular social activities that would allow her practicing her goal of being more attentive in social relationships, but also less demanding activities, such as reading.

\section{$\underline{\text { f. Course of Treatment }}$}

Ms. E was treated by the male psychology masters student (Table 2). She expressed appreciation at the opportunity to talk to a therapist with knowledge regarding BDD as Phase B was initiated, but kept engaging in rituals to the same extent as prior to treatment.

When starting Phase C, Ms. E initially confronted her fear of hair loss. She ruffled her hair, something she reported not having done in years. As she experienced that exposure worked for her, she agreed not to camouflage the skin area of focus. She reported feeling less preoccupied by this fear after having gone to work without make-up for a few days. Spring arrived some sessions into the ERP phase, and the increased exposure to sunlight made her very anxious about damaging her skin. This concern grew more intense as the temperature rose. Eventually, she developed panic attacks and started to avoid leaving home without sun protection. Due to increased rumination and depression, she had trouble concentrating during work and therapy sessions. Ms. E then became too afraid of the possible consequences of sun exposure to continue therapy, and as she began to report increased depression and suicidal ideation, she was offered and accepted medical treatment. ERP was discontinued and she received supportive therapy during evaluation of the medical intervention.

\section{g. Response to Therapy}

Ms. E did not complete ERP, thus the response to all phases cannot be evaluated. As the client reported that the interview and self-report scales increased her distress, we chose not to continue the collection of these data after the client got worse. Thus, this data is missing for Phases $\mathrm{C}$ and $\mathrm{A}_{2}$. The client did, however, choose to continue using the self-report diary. 
The Exposure and Response Prevention in the Treatment of Body Dysmorphic Disorder-A Case Series

According to Figure 1, BDD symptoms were relatively stable during Phases $\mathrm{A}_{1}$ and $\mathrm{B}$, and during Phase $C$ the BDD symptoms intensified somewhat. When Ms. E began ERP in Phase C, she gave verbal reports of improved BDD symptoms. Ms. E was positive and experienced the exposure exercises to be helpful. However, as mentioned above, when spring arrived she reported a sudden worsening of BDD symptoms. Neither the initial improvement as ERP was introduced nor the sudden worsening with spring's arrival is evident in her daily self-ratings. MADRS-S and SDS scores appeared to decrease somewhat over phases $\mathrm{A}_{1}$ and $\mathrm{B}$; however, no reliable change (via the RCI statistic) was achieved.

\section{Client 6: Ms. F}

\section{a. Presenting Problem}

Ms. F was a 19-year-old woman who lived with her parents and had dropped out of high school. In addition to BDD, she was diagnosed with major depression and generalized social phobia. Ms. F showed clear signs of depression, feeling as if her life had been taken away from her, but only acknowledged treatment of her perceived skin problem as the way to regain control over her life. Ratings on standardized measures indicated moderate to severe BDD, marked depression, and problems in global functioning at pre-assessment (Table 3).

\section{b. History}

Ms. F grew up with her mother, father, and a sister. She appreciated her family and reported them to have a close bond. With regards to treatment not focusing on her actual appearance, she had tried counseling sessions and anti-depressant medication, but without any reported results.

\section{c. Assessment of Thoughts, Feelings, and Behaviors as Related to the Client's BDD}

Ms. F perceived herself to be suffering from severe acne, despite being repeatedly reassured by others that this was not the case. She spent hours every day in the bathroom treating her skin with several products and inspecting her face in the mirror from different angles. She regularly saw a beauty therapist for skin treatments, and followed a strict diet that restricted the consumption of any fat, sugar, or any other products believed to potentially cause acne. Due to her concerns, she had stopped studying and seeing friends, and she was practically housebound. She did have a boyfriend, but they only met at Ms. F's parent's house. She occasionally met with friends, but this was associated with tremendous distress and frequent urges to check her appearance in the mirror.

\section{d. Individualized Case Formulation}

Ms. F had experiences of having been teased for acne at school, and this may account for the development of her emotional reactions (fear, distress, and shame), via respondent conditioning, to certain triggers such as her boyfriend, school, friends, and images of herself in mirrors and photos. Ms. F then started treating her skin with products and also started seeing a beauty therapist regularly. At first she experienced these strategies as very helpful; she felt encouraged, happy, and convinced that she had found a solution to her perceived problem (i.e., 
The Exposure and Response Prevention in the Treatment of Body Dysmorphic Disorder-A Case Series

F. Folke, M. Von Bahr, V. Assadi-Talaremi, \& J. Ramnerö

Pragmatic Case Studies in Psychotherapy, http://pcsp.libraries.rutgers.edu

Volume 8, Module 4, Article 2, pp. 255-287, 12-21-12 [copyright by authors]

the strategies were positively reinforced).

However, soon after she felt as though her skin had gotten worse and this made her discouraged, confused, depressed, and convinced that she had to treat her skin but left with no viable skin treatment option. Continuing with skin care procedures (i.e., the products and beauty therapist) did, however, provide her with some comfort and distress reduction (i.e., negative reinforcement). She gradually increased her time in front of the mirror and decreased the time she spent away from home. At home Ms. F got stuck in seeking reassurance about her skin from her family. Reassurance worked temporarily by reducing anxiety but had a negative long-term impact on family relations.

\section{e. Individualized Treatment Plan for ERP}

Ms. F was ambivalent towards formulating goals for therapy. She did wish to be able to be with her boyfriend without hiding her face and without feeling distressed. She also wanted to be able to engage in activities away from home, such as going to restaurants and shopping malls. Ms. F was, however, reluctant to see these as goals for therapy as she was quite convinced that this could only be accomplished by appearance-altering interventions. On the other hand, she did agree to develop a fear and avoidance list of items, but without committing to it. Moreover, she could not differentiate the items into a hierarchy, for all the items in her hierarchy were equally, and extremely, distressing to her (e.g., showing her face to her boyfriend and going to public places not wearing make-up). She was also very reluctant to formulate a response prevention plan that would include stop seeing a beauty therapist for a period of time, spending less time in front of the mirror treating her skin with products, and less time putting make-up on.

\section{$\underline{\text { f. Course of Treatment }}$}

Ms. F was treated by the female psychology masters student (Table 2). During Phase $A_{1}$, she was engaged in the process of self-monitoring. The instructions were well understood and followed. During Phase B, she occasionally felt too depressed or stressed to come to the sessions, or insisted that her mother attend as well for support. The therapist had to motivate and sometimes almost directly persuade the client even to come to the clinic for her sessions. The client explained that she felt invalidated by the mere fact that she had to visit a psychiatric clinic as opposed to a dermatological clinic.

As the therapist presented the behavioral model of BDD in the early stages of Phase C, Ms. F was very skeptical. She seemed to understand the model well but did not think it applied to her. Naturally, she was reluctant to try any exposure exercises and was afraid of the consequences for her skin if she were to give up her compulsions (e.g., stop seeing the beauty therapist). After being encouraged to try it first and evaluate it afterwards, she did go through with one exposure exercise, but this was carried out in a distant and disengaged fashion and was not experienced as helpful. Ms. F did verbally discuss giving up some compulsions, but was never convinced it could help her in the long run. In fact, she was quite certain it would damage her skin. A few sessions into Phase $\mathrm{C}$, she made the choice to end her treatment. 
The Exposure and Response Prevention in the Treatment of Body Dysmorphic Disorder-A Case Series

F. Folke, M. Von Bahr, V. Assadi-Talaremi, \& J. Ramnerö

Pragmatic Case Studies in Psychotherapy, http://pcsp.libraries.rutgers.edu

Volume 8, Module 4, Article 2, pp. 255-287, 12-21-12 [copyright by authors]

\section{g. Response to Therapy}

Ms. F did not complete the ERP, thus her response to all phases cannot be evaluated. The daily self-ratings of BDD symptoms (Figure 1) and the SDS ratings of functioning (Table 3) were relatively stable overall. However, depressive symptoms as measured with MADRS-S (Table 3) did deteriorate reliably $(\mathrm{RCI}=2.25)$ after therapist contact had been initiated during Phase B. This paralleled client verbal reports of being stressed from having to visit the clinic. When the client decided to terminate ERP prematurely, she reported that both the exposure exercises and the response prevention strategies made her more concerned and worried about her appearance.

\section{CONCLUDING EVALUATION OF THERAPY OUTCOMES AND PROCESSES}

The current study was an investigation of the impact of ERP being added to other, more non-specific and less intensive treatment components within a behavioral treatment framework of BDD. A single case experimental design was used within the context of a routine treatment program.

\section{BDD Outcome Results}

All four of the clients who followed through with the ERP treatment achieved improvement that qualified as clinically reliable change (Jacobson \& Truax, 1991) when assessed with a standard BDD interview. Three of the clients (Ms. A., Ms. B, and Ms. C) showed such change directly following ERP in Phase C; and of these, the two for whom there were follow-up data (Ms. A and Ms. B) retained this change at follow-up. The fourth client, Mr. D, showed such change at follow-up.

Detailed analysis of daily self-reports of BDD symptoms showed that most improvements occurred during the ERP intervention in Phase C for three of the clients: Ms. A, Ms. B, and Ms. $\mathrm{C}$. Thus the improvements in functioning assessed with the daily self-report instrument were associated with improvements in BDD in the majority of the clients as measured by the standardized, clinician-administered BDD-YBOCS instrument.

\section{Depression Outcome Results}

Depression outcomes somewhat parallel the BDD outcomes. Three of the four clients who completed Phase C (Ms. A, Ms. B, and Ms. C) showed clinically reliable improvement on the MADR-S depression instrument after Phase C, and of these, the two for whom there was followup data (Ms. A and Ms. B) retained this change at follow-up. The fourth client, Mr. D, began treatment with a relatively low depression score, which was unchanged at follow-up.

These findings are consistent with the idea that depression commonly observed in people with BDD is in many cases maintained or caused by their concerns with appearance and avoidant lifestyle (Phillips, 1999), and thus is reasonably assumed to be most effectively relieved by treating the problems associated with BDD. One client, Ms. F, reported a reliable deterioration in 
The Exposure and Response Prevention in the Treatment of Body Dysmorphic Disorder-A Case Series

F. Folke, M. Von Bahr, V. Assadi-Talaremi, \& J. Ramnerö

Pragmatic Case Studies in Psychotherapy, http://pcsp.libraries.rutgers.edu

Volume 8, Module 4, Article 2, pp. 255-287, 12-21-12 [copyright by authors]

depression following the introduction of therapist contact in phase B. This can perhaps be attributed to the forced exposure that mere therapist contact involves and the fact that the client did not see her problems as psychological, but rather dermatological.

\section{Global Functioning Outcome Results}

The findings on the SDS, the global measure of social, work, and family functioning, in turn paralleled those of the BDD and depression results. All four of the clients who completed the ERP procedures in Phase $\mathrm{C}$ had clinically reliable improvement on the SDS measure either post-Phase $\mathrm{C}$ or at follow-up. These findings provide empirical support for what seems clinically straightforward: BDD causes depression and interferes with social, work, and family functioning.

\section{The Role of ERP}

There was considerable variability in the clients' response to the current treatment. It is noteworthy that the three clients with the most alarming levels of psychopathology at preassessment, made the largest overall improvements in terms of BDD, depression, and functioning. In contrast to this, experienced therapists working with BDD often report that treatment refusal or drop out is more common in clients with more severe BDD (Wilhelm, Otto, Lohr, \& Deckersbach, 1999).

There were also differences in the two non-improved clients. Ms. F was reluctant to try ERP at all and ended treatment after only one session of ERP. She did not perceive the treatment as a helpful option as she was convinced that her physical flaw was real. On the other hand, the other non-improved client, Ms. E, was somewhat less reluctant towards ERP and actually experienced benefits from it, until her BDD got worse due to circumstances unrelated to therapy, that is, the coming of spring during the therapy and the client's rising concern of skin damage from going out into the sun. Thus, the two clients who did not improve were not similar to each other in regards to their attitudes towards the treatment model.

It should also be noted that all clients in our treatment reported at least some initial reluctance towards ERP. However, five out of six clients reported feeling encouraged after a few exposure sessions (although one of them, Ms. E, did drop out). Two of the clients (Mr. D and Ms. E) did experience an increased distress due to their preoccupation with appearance during the ERP. However, they both attributed these increased symptoms to circumstances unrelated to therapy that occurred during Phase $\mathrm{C}$ and that exacerbated their skin concerns. Mr. D developed an infection during Phase C, and Ms. E had rising concern about skin damage from the sun with the coming of spring. Mr. D chose to continue ERP and made significant progress towards his personal goals, although he did not show symptomatic relief until the scheduled follow-up interview. Ms. E chose to end ERP prematurely despite initial progress.

\section{Client Characteristics}

Based on the small number of clients in the study, any conclusive comment about client gender is unwarranted. However, the information in Table 2 suggests that gender was not an issue in outcome since the only male client had a good therapeutic outcome, and the female and male therapist were equally successful in delivering treatment (i.e., two good outcomes and one 
The Exposure and Response Prevention in the Treatment of Body Dysmorphic Disorder-A Case Series

F. Folke, M. Von Bahr, V. Assadi-Talaremi, \& J. Ramnerö

Pragmatic Case Studies in Psychotherapy, http://pcsp.libraries.rutgers.edu

Volume 8, Module 4, Article 2, pp. 255-287, 12-21-12 [copyright by authors]

poor outcome each).

Over the cases in this study, we were not able to clearly identify any further, specific client or therapist characteristics common to achieving good or poor outcome, or to dropping out of treatment. However, the data do suggest that a possible candidate for a predictor of good outcome may well be a client's early positive experiences of ERP. If so, this is especially notable against the background of the initial skepticism towards the treatment shown by the clients. Overall, early positive experiences with ERP appear to be important, and in addition, continued active participation in ERP throughout therapy seems necessary for improvement to occur. Previous research has indeed found that clients who show active engagement early in exposurebased treatments tend to achieve better outcomes (Ramnerö \& Öst, 2007).

\section{Study Limitations}

This is a small case-series study made within the context of a regular treatment facility and as such, it inevitably has several limitations. Although we used a design aimed at differentiating the effect of ERP from self-monitoring and therapist contact, we need to be cautious in interpreting the results. It should be noted that we used an add-on design that does not allow for any firm differentiation of such effects. The observed variations in some clients' baseline registrations of BDD symptoms make any conclusions about effects due to the active treatment less certain. Neither are we in a position to convincingly argue that other factors, unrelated to therapy, may have caused the observed improvements.

However, previous research indicates that spontaneous recovery in BDD is unlikely (Veale et al., 1996). The fixed order of interventions may also have affected results in one direction. It is an obvious possibility that, especially during Phase B, several therapeutic processes were started, such as establishing a working alliance between the client and therapist that laid the foundation for later improvement. Even though BDD-symptoms did not tend to change during the preexposure phases, it may well be assumed that this part of the therapeutic regime sets the stage for the further change process, especially since exposure treatment tends to be inherently challenging and could by definition be considered putting demands on the client to move out of his or her safety zone. However, since this study made no attempt to control for order of deliverance of treatment components, no conclusions can be drawn in either direction. Looking at the process, though, it seems that in most cases a more pronounced change occurred during the ERP Phase C.

The risk for therapy allegiance effects in relation to the clinic's commitment to delivering behavioral treatment should also be acknowledged here. A number of measures could have been taken to improve the internal validity of the design. Multiple baselines of different lengths for different clients could have made claims about causality more reliable. However, due to the circumstances of treatment delivery, and ethical concerns with requiring some clients to wait longer for treatment, we did not consider this a viable option. Randomizing the order of interventions could have been one way of controlling for order effects. However, since this treatment was conducted within the routine treatment offered to BDD clients at the clinic, this would have been a deviation that was not deemed possible to carry out without extensive violation of these routines. 
The Exposure and Response Prevention in the Treatment of Body Dysmorphic Disorder-A Case Series

From a case-study perspective, it would have been important to wait for baseline registrations to stabilize before any intervention. Again, ethical concerns of withholding treatment and also our own concerns, based on the preconception that unduly long baseline registration would be detrimental for treatment motivation, guided the decision of a pre-set time period for this phase. With the results in hand, we note that clients in the current study experienced the baseline registration as most acceptable in the current form. Interviewers blind to the treatment design would of course have been preferential, but again this was the limitation we had to accept when conducting the study within the clinic.

The therapists in the current treatments were students. One might argue that stronger evidence of positive outcome in the ERP Phase $C$ was due to the students being more skilled in ERP than in the supportive therapeutic techniques associated with Phase B. This is, however, unlikely as the students were recruited from the five-year doctoral psychology program, where they are trained in a variety of approaches and psychological methods, and the opportunity to receive specific training in CBT is introduced only during the last years. It should be noted that despite the known complexity of BDD, the student treatments in this study achieved outcomes well comparable to other treatment studies of BDD.

\section{Conclusion}

This study highlights a number of important issues. It suggests, as does previous research, that BDD can be viably treated with ERP in a limited number of sessions. It also indicates that the intervention of ERP is temporally associated with a more pronounced change process in BDD-symptoms, as well as in depression and social functioning. ERP can thus be assumed to constitute a vital element in effective treatment of BDD.

It is of particular interest that the beneficial effects observed during the exposure exercises most often stood in sharp contrast to the client's initial skepticism towards the treatment approach. The quantitative results indicate that beneficial effects of treatment occurred during the ERP phase for three of the four clients completing the ERP treatment, and thus suggest that this component should, in spite of clients' almost reflexive, initial skepticism, be considered essential in the behavioral treatment of BDD, even if it requires active persuasion from the therapist. In this regard, it should be noted that in Greenberg et al.'s (2010) study of Marcy, as mentioned earlier, at the end of therapy in response to the question about what had been most helpful about the treatment, Marcy mentioned ERP in addition to "mirror retraining," and "labeling self-defeating thoughts" (p. 254).

The present study also highlights how a series of single case experimental design studies such as this can be advantageously carried out in routine clinical contexts, and that this methodology can serve as a means of involving students in the research of treatment of complex psychiatric problems.

Finally, the variety of reactions of the six clients to a similar, structured treatment approach argue for the importance of tailoring therapy to the individual needs of clients. All in 
The Exposure and Response Prevention in the Treatment of Body Dysmorphic Disorder-A Case Series

F. Folke, M. Von Bahr, V. Assadi-Talaremi, \& J. Ramnerö

Pragmatic Case Studies in Psychotherapy, http://pcsp.libraries.rutgers.edu

Volume 8, Module 4, Article 2, pp. 255-287, 12-21-12 [copyright by authors]

all, we believe that the results of this case series serve to be replicated in larger clinical outcome studies.

\section{REFERENCES}

American Psychiatric Association. (1994). Diagnostic and statistical manual of mental disorders (4th ed.). Washington, DC: American Psychiatric Association.

Barlow, D.H., \& Nock, M.K. (2008). Single case experimental designs: Strategies for studying behavior change (3rd Edition). Boston: Allyn \& Bacon.

Buhlmann, U., Reese, H. E., Renaud, S., \& Wilhelm, S. (2008). Clinical considerations for the treatment of body dysmorphic disorder with cognitive-behavioral therapy. Body Image, 5 , 39-49.

Cuijpers, P., van Straten, A., Andersson, G., \& van Oppen, P. (2008). Psychotherapy for depression in adults: A meta-analysis of comparative outcome studies. Journal of Consulting and Clinical Psychology, 76, 909-922.

DeMarco, L. M., Li, L. C., Phillips, K. A., \& McElroy, S. L. (1998). Perceived stress in body dysmorphic disorder. The Journal of Nervous and Mental Disease, 186, 724-726.

Diefenbach, G. J., Abramowitz, J. S., Norberg, M. M., \& Tolin, D. F. (2007). Changes in quality of life following cognitive-behavioral therapy for obsessive-compulsive disorder. Behaviour Research and Therapy 45, 3060-3068.

Fantino, B., \& Moore, N. (2009). The self-reported Montgomery-Åsberg depression rating scale is a useful evaluative tool in major depressive disorder. BMC Psychiatry 9:26

Foa, E. B., Abramowitz, J. S., Franklin, M. E., \& Kozak, M. J. (1999). Feared consequences, fixity of belief, and treatment outcome in patients with obsessive-compulsive disorder. Behavior Therapy, 30, 717-724.

Greenberg, J.L., Markowitz, S., Petronko, M.R., Taylor, C.E., Wilhelm, S., \& Wilson, G. T. (2010). Cognitive-behavioral therapy for adolescent body dysmorphic disorder. Cognitive and Behavioral Practice, 17, 248-258.

Greenberg, J.L., \& Wilhelm, S. (2011). Cognitive-behavioral therapy for body dysmorphic disorder: A review and future directions. International Journal of Cognitive Therapy, 4, 349-362.

Jacobson, N. S., \& Truax, P. (1991). Clinical significance:A statistical approach to defining meaningful change in psychotherapy research. Journal of Consulting and Clinical Psychology, 59, 12-19.

Kazdin, A. E. (1982). Single-case research designs: Methods for clinical and applied settings. New York: Oxford University Press.

Leon, A.C., Olfson, M., Portera, L., Farber, L., \& Sheehan, D.V. (1997), Assessing psychiatric impairment in primary care with the Sheehan disability scale. International Journal of Psychiatry in Medicine, 27, 93-105.

Montgomery, S. A., \& Åsberg, M. (1979). A new depression scale designed to be sensitive to change. The British Journal of Psychiatry, 134, 382-389.

National Collaborating Centre for Mental Health (2005) Obsessive-Compulsive Disorder: Core interventions in the treatment of Obsessive-Compulsive Disorder and Body Dysmorphic Disorder (Clinical guideline CG31). British Psychological Society \& Royal College of Psychiatrists. 
The Exposure and Response Prevention in the Treatment of Body Dysmorphic Disorder-A Case Series

F. Folke, M. Von Bahr, V. Assadi-Talaremi, \& J. Ramnerö

Pragmatic Case Studies in Psychotherapy, http://pcsp.libraries.rutgers.edu

Volume 8, Module 4, Article 2, pp. 255-287, 12-21-12 [copyright by authors]

Neziroglu, F., \& Khemlani-Patel, S. (2003). Therapeutic approaches to body dysmorphic disorder. Brief Treatment and Crisis Intervention, 3, 307-322.

Phillips, K. A., McElroy, S. L., Keck, P. E., Pope, H. G., \& Hudson, J. I. (1993). Body dysmorphic disorder - 30 cases of imagined ugliness. American Journal of Psychiatry, 150, 302-308.

Phillips, K. A., \& Diaz, S. F. (1997). Gender differences in body dysmorphic disorder. The Journal of Nervous and Mental disease, 185, 570-577.

Phillips, K. A., Hollander, E., Rasmussen, S. A., Aronowitz, B. R., DeCaria, C., \& Goodman, W. K. (1997). A severity rating scale for body dysmorphic disorder: Development, reliability, and validity of a modified version of the Yale-Brown Obsessive Compulsive Scale. Psychopharmacology Bulletin, 33, 17-22.

Phillips, K. A., Dwight, M.M., \& McElroy, S. L. (1998). Efficacy and safety of fluvoxamine in body dysmorphic disorder. Journal of Clinical Psychiatry. 59, 165-171.

Phillips, K. A. (1999). Body dysmorphic disorder and depression: Theoretical considerations and treatment strategies. Psychiatric Quarterly, 70, 313-331.

Phillips, K. A. (2000). Quality of life for patients with body dysmorphic disorder. The Journal of Nervous and Mental Disease, 188, 170-175.

Phillips, K. A. (2005). The broken mirror: Understanding and treating body dysmorphic disorder. New York: Oxford University Press.

Phillips, K. A., Coles, M. E., Menard, W., Yen, S., Fay, C., \& Weisberg, R. B. (2005a). Suicidal ideation and suicide attempts in body dysmorphic disorder. The Journal of Clinical Psychiatry, 66, 717-725.

Phillips, K. A., Menard, W., Fay, C., \& Pagano, M. E. (2005b). Psychosocial functioning and quality of life in body dysmorphic disorder. Comprehensive Psychiatry, 46, 254-260.

Phillips, K. A., Menard, W., Fay, C., \& Weisberg, R. (2005c). Demographic characteristics, phenomenology, comorbidity, and family history in 200 individuals with body dysmorphic disorder. Psychosomatics, 46, 317-325.

Phillips, K. A., Menard, W., Pagano, M. E., Fay, C., \& Stout, R. L. (2006). Delusional versus nondelusional body dysmorphic disorder: Clinical features and course of illness. Journal of Psychiatric Research, 40, 95-104.

Rabinowitz, D., Neziroglu, F., \& Roberts, M. (2007). Clinical application of a behavioral model for the treatment of body dysmorphic disorder. Cognitive and Behavioral Practice, 14, 231-237.

Ramnerö, J., \& Öst, L-G. (2007). Therapists’ and clients’ perception of each other and working alliance in the behavioral treatment of panic disorder and agoraphobia. Psychotherapy Research, 17, 328-337.

Sheehan, D. V., Harnett-Sheehan, K., \& Raj, B. A. (1996). The measurement of disability. International Clinical Psychopharmacology, 11, 89-95.

Sheehan, D.V., \& Sheehan, K.H. (2008). Assessing treatment effects in clinical trials with the Discan metric of the Sheehan Disability Scale. International Clinical Psychopharmacology, 23, 70-83.

Sheehan, D. V., Lecrubier, Y., Sheehan, K. H., Amorim, P., Janavs, J., Weiller, E., et al. (1998). The mini-international neuropsychiatric interview (MINI): The development and validation of a structured diagnostic psychiatric interview for DSM-IV and ICD-10. Journal of Clinical Psychiatry, 59(Suppl20), 22-33

Sturmey, P. (1996). Functional analysis in clinical psychology. Chichester; John Wiley \& Sons. 
Svanborg, P, \& Ekselius, L. (2003). Self-assessment of DSM-IV criteria for major depression in psychiatric out- and inpatients. Nordic Journal of Psychiatry, 57, 291 - 296

Svanborg, P., \& Åsberg, M. (1994). A new self-rating scale for depression and anxiety states based on the comprehensive psychopathological rating scale. Acta Psychiatr Scand, 89, 21-28.

Svanborg, P., \& Åsberg, M. (2001). A comparison between the Beck Depression Inventory (BDI) and the self-rating version of the Mongomery Åsberg Depression Rating Scale (MADRS). Journal of Affective Disorders, 64, 203-216.

Veale, D., Gournay, K., Dryden, W., Boocock, A., Shah, F., Willson, R., et al. (1996). Body dysmorphic disorder: A cognitive behavioural model and pilot randomised controlled trial. Behaviour Research and Therapy, 34, 717-729.

Wilhelm, S., Otto, M. W., Lohr, B., \& Deckersbach, T. (1999). Cognitive behavior group therapy for body dysmorphic disorder: A case series. Behaviour research and therapy, 37, 71-75. 
Table 1: Summary of Relevant Client Demographic Variables and Other Characteristics

\begin{tabular}{|c|c|c|c|c|c|c|}
\hline Client & Age & Sex & $\begin{array}{c}\text { Civil and } \\
\text { Occupational } \\
\text { Status }\end{array}$ & $\begin{array}{l}\text { Primary } \\
\text { Physical } \\
\text { area of } \\
\text { Concern }\end{array}$ & $\begin{array}{c}\text { Primary and } \\
\text { Comorbid } \\
\text { Diagnoses }\end{array}$ & Medication \\
\hline Ms. A & 24 & Female & $\begin{array}{l}\text { Single, } \\
\text { Student }\end{array}$ & Face & $\begin{array}{c}\text { BDD, Co- } \\
\text { morbid Major } \\
\text { Depression, and } \\
\text { Social Phobia } \\
\text { (Generalized) }\end{array}$ & $\begin{array}{c}\text { Antidepressant } \\
\text { medication }\end{array}$ \\
\hline Ms. B & 17 & Female & $\begin{array}{c}\text { Living with } \\
\text { parents } \\
\text { Student }\end{array}$ & Face & $\begin{array}{c}\text { BDD, Co- } \\
\text { morbid Major } \\
\text { Depression and } \\
\text { Social Phobia } \\
\text { (Generalized) }\end{array}$ & $\begin{array}{c}\text { Antidepressant } \\
\text { medication }\end{array}$ \\
\hline Ms. C & 32 & Female & $\begin{array}{l}\text { Single, } \\
\text { Student }\end{array}$ & Facial skin & $\begin{array}{l}\text { BDD, Co- } \\
\text { morbid Major } \\
\text { Depression }\end{array}$ & $\begin{array}{c}\text { Antidepressant } \\
\text { medication }\end{array}$ \\
\hline Mr. D & 20 & Male & $\begin{array}{c}\text { Living with } \\
\text { one parent, } \\
\text { Student }\end{array}$ & $\begin{array}{l}\text { Skin and } \\
\text { nose }\end{array}$ & $\begin{array}{c}\text { BDD, Co- } \\
\text { morbid Major } \\
\text { Depression and } \\
\text { Social Phobia } \\
\text { (Generalized) }\end{array}$ & None \\
\hline Ms. E & 35 & Female & $\begin{array}{l}\text { Living with } \\
\text { boyfriend, } \\
\text { Employee }\end{array}$ & $\begin{array}{c}\text { Hair and } \\
\text { facial skin }\end{array}$ & $\begin{array}{c}\text { BDD, Co- } \\
\text { morbid Major } \\
\text { Depression }\end{array}$ & None \\
\hline Ms. F & 19 & Female & $\begin{array}{l}\text { Living with } \\
\text { parents, } \\
\text { student }\end{array}$ & Facial skin & $\begin{array}{c}\text { BDD, Co- } \\
\text { morbid Major } \\
\text { Depression and } \\
\text { Social Phobia } \\
\text { (Generalized) }\end{array}$ & None \\
\hline
\end{tabular}


Table 2: Client and Therapist Gender and Treatment Outcome

\begin{tabular}{cccc}
\hline Client & Client Gender & Therapist Gender & Outcome \\
& & & Good \\
Ms. A & Female & Male & Good \\
Ms. B & Female & Female & Good \\
Ms. C & Female & Female & Good \\
Mr. D & Male & Male & Poor \\
Ms. E & Female & Male & Poor \\
Ms. F & Female & Female & \\
\hline
\end{tabular}


Table 3: Total Scores on Standardized Self-report Scales and Interviews Regarding BDD, Depression, and Global Functioning

\begin{tabular}{|c|c|c|c|c|c|c|c|c|c|c|c|c|c|c|c|}
\hline & \multicolumn{5}{|c|}{$\begin{array}{c}\text { BDD-YBOCS } \\
\text { (higher score, greater BDD) } \\
\text { (clinical cut off }=20)\end{array}$} & \multicolumn{5}{|c|}{$\begin{array}{c}\text { MADRS-S } \\
\begin{array}{l}\text { (higher score, greater depression) } \\
(\text { estimate of clinical cut-off }=1.7 \text { ) }\end{array} \\
\end{array}$} & \multicolumn{5}{|c|}{$\begin{array}{c}\text { SDS } \\
\begin{array}{l}\text { (higher score, lower global functioning) } \\
\text { (estimate of clinical cut-off }=10.64 \text { ) }\end{array}\end{array}$} \\
\hline & Pre & Post A & Post B & Post C & $\begin{array}{c}\text { Follow- } \\
\text { Up }\end{array}$ & Pre & Post A & Post B & Post C & $\begin{array}{c}\text { Follow- } \\
\text { Up }\end{array}$ & Pre & Post A & Post B & Post C & $\begin{array}{c}\text { Follow- } \\
\text { Up }\end{array}$ \\
\hline Ms. A & 40 & - & - & $18^{*}$ & $13^{*}$ & 15 & 11.5 & 15.5 & $4.5^{*}$ & $2.5^{*}$ & 24 & 18 & 18 & $4^{*}$ & 7 \\
\hline Ms. C & 32 & - & - & $10 *$ & $X$ & 13.5 & 13.5 & 9 & $1.5^{*}$ & $X$ & 10 & 19 & $20^{\wedge}$ & 1 & $\mathrm{X}$ \\
\hline Mr. D & 24 & - & - & 19 & $15 *$ & 9.5 & 6.5 & 6 & 11 & 5.5 & 19 & 13 & $7^{*}$ & 18 & $7^{*}$ \\
\hline Ms. E & 27 & - & - & $\mathrm{X}$ & $\mathrm{X}$ & 9.5 & 7 & 6.5 & $\mathrm{X}$ & $\mathrm{X}$ & 15 & 10 & 11 & $X$ & $\mathrm{X}$ \\
\hline
\end{tabular}

Note: "-" = Measures not collected; "X" = Missing data;

BDD-YBOCS = The Body Dysmorphic Disorder Modification of the Yale-Brown Obsessive-Compulsive Inventory Scale.

Total range: $0-48$, mean score in a clinical population $=30.7$, mean score in a treated sample $=14.7$.

Cut-off scores based on clinical experience:

$>20$ (current BDD), >24 (moderate BDD), scores in the 30's (moderate to severe BDD), scores in the 40's (very severe BDD).

MADRS-S = Montgomery-Åsberg Depression Rating Scale (self rating version). Total range: 0-27, mean score in a clinical population: 14.5, mean score in a full remission depression sample: 1.7 .

SDS = Sheehan Disability Scale. Total range: 0-30, mean score in a clinical population $=14.2-23.1$, mean score in a treated sample $=10.64$.

“*” indicates that reliable change (improvement) (i.e., $\mathrm{RCI}<-1.96, \mathrm{p}<.05$ ) has been achieved in comparison to pre-assessment.

“ $\wedge$ ” indicate that reliable change (deterioration) (i.e., RCI $>1.96, \mathrm{p}<.05$ ) has been achieved in comparison to pre-assessment. 
Figure 1: Daily Self-Report Diaries For BDD-Related Symptoms for Each Client.

Note: Each point represents a daily average score (a compound of five items, each ranging from 0-8). Treatment phases are separated by the dotted lines. Descending lines indicate improvements. $\mathrm{M}=$ mean; $\mathrm{SD}=$ standard deviation; $\mathrm{SCS}=$ standardized change score; $\mathrm{MV}=$ missing values.

Ms. A

\section{$\mathrm{ARRRR}_{1}$ : Self-} monitoring

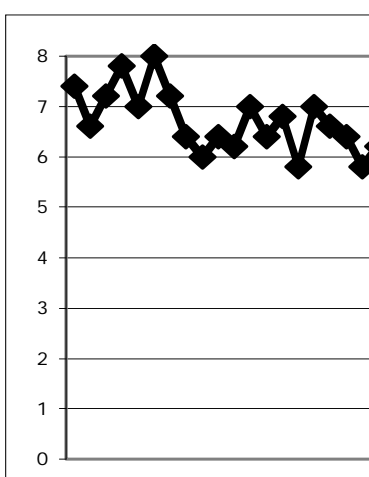

M: 6.64

Sd: 0.68

MV: 0\%

Ms. B

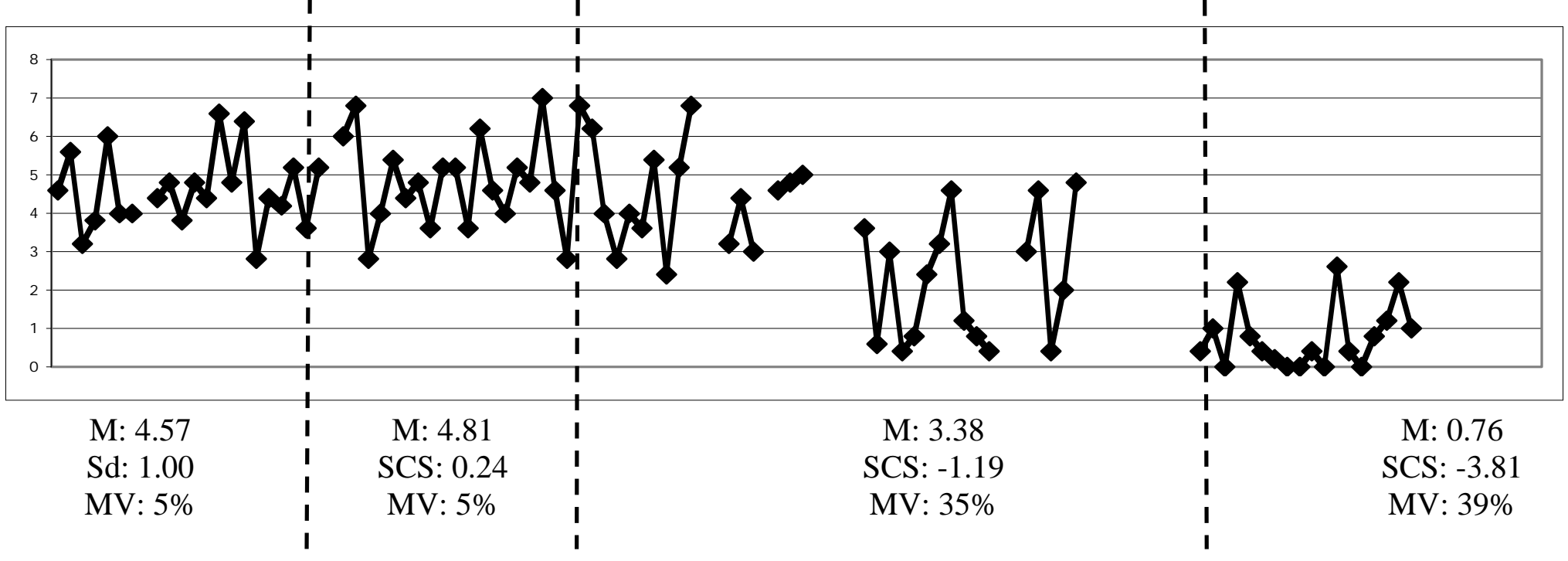

\section{M: 6.23}

SCS: -0.53

MV: 0\%
C: Exposure and response prevention

I

$A_{2}$ : Self-monitoring

M: 4.85

SCS: -2.63

MV: 4\%
M: 3.86

SCS: -4.09

MV: 0\% 
UFigure 1: Daily Self-Report Diaries For BDD-Related Symptoms for Each Client (continued)

Note: Each point represents a daily average score (a compound of five items, each ranging from 0-8). Treatment phases are separated by the dotted lines. Descending lines indicate improvements. $\mathrm{M}=$ mean; $\mathrm{SD}=$ standard deviation; $\mathrm{SCS}=$ standardized change score; $\mathrm{MV}=$ missing values.

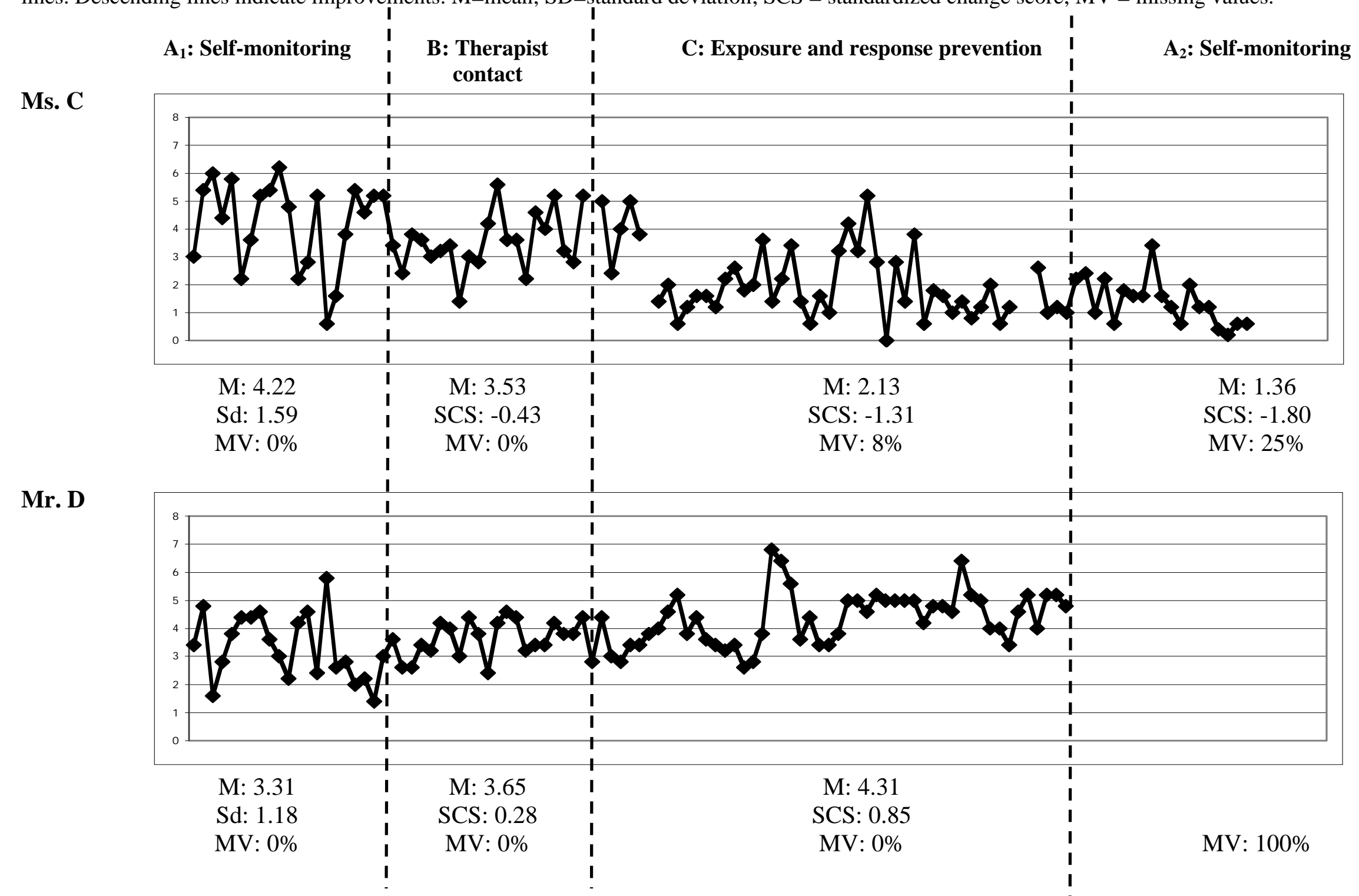


Figure 1. Daily Self-Report Diaries For BDD-Related Symptoms for Each Client (continued)

Note: Each point represents a daily average score (a compound of five items, each ranging from 0-8). Treatment phases are separated by the dotted lines. Descending lines indicate improvements. $\mathrm{M}=$ mean; $\mathrm{SD}=$ standard deviation; SCS = standardized change score; $\mathrm{MV}=$ missing values.

\section{$\mathrm{A}_{1}$ : Self-monitoring}

\section{I}

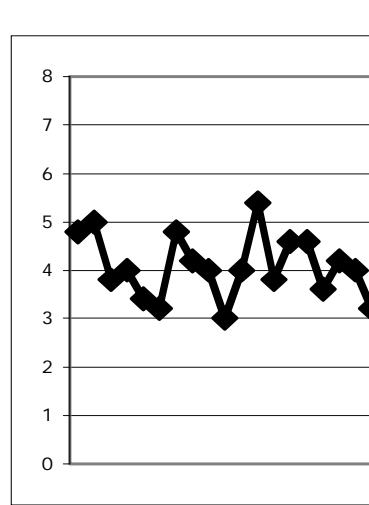

M: 4.05

Sd: 0.67

MV: 0\%

Ms. F

\section{B: Therapist} contact

I

\section{C: Exposure and response prevention}

ind

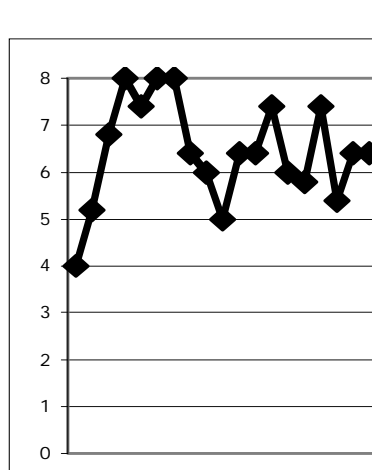

M: 6.40

Sd: 1.05

MV: 0\%
$\mathrm{M}: 6.64$

SCS: 0.23

MV: 0\%
M: 4.20

SCS: 0.22

MV: 0\%

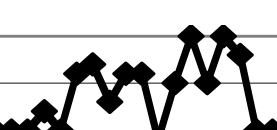

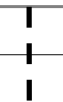

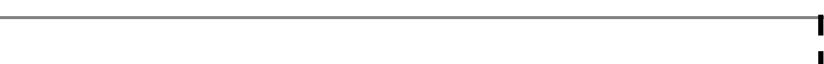

I

\section{$\mathrm{A}_{2}$ : Self-monitoring}

